\title{
Experimental bladder regeneration using a poly-L-lactide/silk fibroin scaffold seeded with nanoparticle-labeled allogenic bone marrow stromal cells
}

\author{
This article was published in the following Dove Press journal: \\ International Journal of Nanomedicine \\ 6 September 2016 \\ Number of times this article has been viewed
}

\begin{abstract}
Natalia M Yudintceva, ' Yulia A Nashchekina, ${ }^{1,2}$ Miralda I Blinova,' Nadezhda $\vee$ Orlova, ${ }^{3}$ Alexandr N Muraviov, ${ }^{3}$ Tatiana I Vinogradova, ${ }^{3}$ Magomed G Sheykhov, ${ }^{3}$ Elena Y Shapkova, ${ }^{3}$ Dmitriy V Emeljannikov, ${ }^{3}$ Petr K Yablonskii, ${ }^{3,4}$ Igor A Samusenko, ${ }^{5}$ Anastasiya L Mikhrina, ${ }^{6}$ Artem V Pakhomov, ${ }^{7}$ Maxim A Shevtsov 1,7,8

'Department of Cell Culture, Institute of Cytology of the Russian Academy of Sciences (RAS), ${ }^{2}$ Nanotechnology and Telecommunications, Institute of Physics, Peter the Great St Petersburg Polytechnic University, ${ }^{3}$ Department of Urology, Federal State Institution Saint Petersburg Research Institute of Phthisiopulmonology, Ministry of Health of Russia, ${ }^{4}$ Faculty of Medicine, Federal State Budgetary Institute, ${ }^{5}$ Department of Pathology, Federal State Budgetary Institute "Nikiforov Russian Centre of Emergency and Radiation Medicine" of the Ministry of Health of Russia, ${ }^{6}$ Department of Pathomorphology, I.M. Sechenov Institute of Evolutionary Physiology and Biochemistry of the Russian Academy of Science, ${ }^{7}$ Department of Radiology, Federal Almazov North-West Medical Research Center, ${ }^{8}$ Department of Experimental Medicine, First I.P. Pavlov State Medical University of St Petersburg, St Petersburg, Russia
\end{abstract}

Correspondence: Natalia M Yudintceva Department of Cell Culture, Institute of Cytology of the Russian Academy of Sciences (RAS), Tikhoretsky Ave 4, St Petersburg 194064, Russia

Tel +78122977450

$\mathrm{Fax}+78122970341$

Email yudintceva@mail.ru

\begin{abstract}
In the present study, a poly-L-lactide/silk fibroin (PL-SF) bilayer scaffold seeded with allogenic bone marrow stromal cells (BMSCs) was investigated as a potential approach for bladder tissue engineering in a model of partial bladder wall cystectomy in rabbits. The inner porous layer of the scaffold produced from silk fibroin was designed to promote cell proliferation and the outer layer produced from poly-L-lactic acid to serve as a waterproof barrier. To compare the feasibility and efficacy of BMSC application in the reconstruction of bladder defects, 12 adult male rabbits were divided into experimental and control groups (six animals each) that received a scaffold seeded with BMSCs or an acellular one, respectively. For BMSC tracking in the graft in in vivo studies using magnetic resonance imaging, cells were labeled with superparamagnetic iron oxide nanoparticles. In vitro studies demonstrated high intracellular incorporation of nanoparticles and the absence of a toxic influence on BMSC viability and proliferation. Following implantation of the graft with BMSCs into the bladder, we observed integration of the scaffold with surrounding bladder tissues (as detected by magnetic resonance imaging). During the follow-up period of 12 weeks, labeled BMSCs resided in the implanted scaffold. The functional activity of the reconstructed bladder was confirmed by electromyography. Subsequent histological assay demonstrated enhanced biointegrative properties of the PL-SF scaffold with cells in comparison to the control graft, as related to complete regeneration of the smooth muscle and urothelium tissues in the implant. Confocal microscopy studies confirmed the presence of the superparamagnetic iron oxide nanoparticle-labeled BMSCs in newly formed bladder layers, thus indicating the role of stem cells in bladder regeneration. The results of this study demonstrate that application of a PL-SF scaffold seeded with allogenic BMSCs can enhance biointegration of the graft in vivo and support bladder tissue regeneration and function.
\end{abstract}

Keywords: bladder, bone marrow stromal cells, scaffold, superparamagnetic iron oxide nanoparticles, tissue engineering, stem cells

\section{Introduction}

Bladder reconstruction is still one of the greatest surgical challenges. Currently, augmentation cystoplasty using gastrointestinal segments is the most frequently applied method, which often leads to various complications including metabolic acidosis, urolithiasis, recurrent urinary tract infections, and tissue contracture. ${ }^{1,2}$ Furthermore, it was shown that the level of differentiation of the epithelial cells of the small intestine submucosa is low and they cannot functionally replace the urothelium in the case of 
autoplasty of the bladder with the application of gastrointestinal tract fragments. ${ }^{3,4}$ Nongastrointestinal alternatives (eg, fascia, skin, omentum, placenta) used for bladder augmentation also demonstrated a high risk of complications. ${ }^{1}$

Application of transplantable autologous urinary bladder neo-organs produced by tissue engineering clearly demonstrated the feasibility and efficacy of this method in reconstruction of the bladder. ${ }^{5}$ Subsequent clinical application of autologous engineered bladder tissues reported by Atala further proved the efficacy of engineered tissues for cystoplasty. ${ }^{6}$ The significant limitation of the proposed technique is the availability of autologous tissues for engineering that are significantly reduced or pathologically changed in patients with various diseases including a contracted bladder due to tuberculosis, tumors, etc. ${ }^{7}$ A plausible approach for bladder regeneration could be based on the application of a scaffold seeded with allogenic cells. To date, decellularized natural (based on bladder or small intestine submucosa) and synthetic scaffolds have been proposed. ${ }^{8-10}$

Although natural scaffolds were shown to have a therapeutic efficacy, application of synthetic scaffolds is preferential due to the possibility of producing individualized forms with defined physicochemical characteristics.

An ideal biocompatible scaffold for bladder regeneration should maintain a three-dimensional structure with appropriate mechanical properties (ie, strength, elasticity), tunable biodegradability and a waterproof barrier function. ${ }^{11}$ In the present study, we aimed to use a bilayer scaffold based on poly-L-lactide/silk fibroin (PL-SF) for bladder augmentation. The inner porous layer of the scaffold was designed to promote cell proliferation and the second outer layer to serve as a barrier to fluid penetration. The porous layer was produced from native silk fibroin (SF) fibers. SF is a unique natural fibrous protein that has a unique array of properties, including high structural strength and elasticity and diverse processing plasticity. ${ }^{12}$ Poly-L-lactide was applied due to its high hydrophobicity that could be employed for the production of the outer waterproof layer of the scaffold. ${ }^{13,14}$

To increase the biocompatibility of the synthesized graft we applied bone marrow stromal cells (BMSCs) that were previously shown to enhance bladder regeneration. ${ }^{15,16}$ BMSCs have immunosuppressive effects, ${ }^{17-19}$ high proliferative potential and the ability to differentiate into different tissue lines ${ }^{20-22}$ including cells of the urothelium. ${ }^{23-25}$

For stem cell tracking in the graft, BMSCs were labeled with superparamagnetic iron oxide nanoparticles (SPIONs) which, due to their superparamagnetic behavior, can be applied as contrast agents for magnetic resonance imaging (MRI). ${ }^{26,27}$ SPIONs have increased transverse relaxivity, $r 2$, in comparison to paramagnetic gadolinium-based contrast agents, suggesting the possibility for cell imaging in a clinical MRI scanner. Previously, several studies reported the feasibility of the application of iron-labeled cells for in vivo tracking. ${ }^{28-30}$

The implanted scaffolds seeded with iron-labeled BMSCs were analyzed for biocompatibility and feasibility in bladder regeneration in a model of partial bladder wall cystectomy in New Zealand rabbits.

\section{Materials and methods Fabrication of the bilayer PL-SF scaffold}

SF was obtained from silkworm Bombyx mori cocoons. Natural silk obtained from $B$. mori cocoons was boiled for 1 hour in $0.03 \mathrm{M} \mathrm{NaHCO}_{3}$ and thoroughly rinsed with distilled water. Scaffolds were prepared by a particle-leaching method. The poly-L-lactic acid $(\eta=0.49 \mathrm{dL} / \mathrm{g})$ (SigmaAldrich, Carlsbad, CA, USA) was dissolved in $2 \%(\mathrm{w} / \mathrm{v})$ chloroform (Reachem, Moscow, Russia) at $20^{\circ} \mathrm{C} . \mathrm{NaCl}$ particles (100-150 mm) were mixed with SF and then put into polytetrafluoroethylene wells (diameter, $18 \mathrm{~mm}$; height, $3 \mathrm{~mm}$ ), then the polymer solution was added to the salt/SF mixture. Following overnight air drying, the same mixture of polymer solution was added to the surface of the synthesized composites. To remove the remaining solvent, composites were air-dried for 48 hours with subsequent vacuum drying for 24 hours. The resulting polymer/salt/SF composites were immersed for 24 hours in distilled water for desalting. The resulting scaffold consisted of two layers: 1) polymer/ salt/SF and 2) poly-L-lactide polymer. The scaffolds were sterilized using an ozone gas concentration of $200 \mathrm{ppm}$ for 120 minutes at a relative humidity of $80 \%$. For analysis of the graft structure, samples were examined using scanning electron microscopy (SEM) (FE-SEM; JSM-6340F, JEOL, Tokyo, Japan).

\section{Isolation of BMSCs}

Bone marrow from the femur of New Zealand rabbits was extruded by flushing with $\alpha$-minimum essential medium (MEM) (Lonza, Allendale, NJ, USA) supplemented with 10\% fetal bovine serum (FBS; HyClone, Logan, UT, USA), $100 \mathrm{U} / \mathrm{mL}$ penicillin (Sigma-Aldrich, WGK Germany), and $100 \mu \mathrm{g} / \mathrm{mL}$ streptomycin (Sigma-Aldrich, WGK Germany). The marrow plug suspension was dispersed by pipetting, filtered through a $70 \mu \mathrm{m}$ mesh nylon filter (Becton Dickinson Biosciences, Bedford, MA, USA), and centrifuged at $400 \times g$ for 5 minutes. The pellet was resuspended in Red Blood Cell Lysis Solution (0.154 $\mathrm{M} \mathrm{NH}_{4} \mathrm{Cl}$, $10 \mathrm{mM} \mathrm{KHCO}_{3}$, and $0.1 \mathrm{mM}$ ethylenediaminetetraacetic 
acid [EDTA]; Panreac, Barcelona, Spain) for 5 minutes and centrifuged at $400 \times g$ for 5 minutes. Cells $\left(1 \times 10^{7}\right)$ were seeded into $100 \mathrm{~mm}$ culture dishes (Nunc, Thermo Fisher Scientific, Waltham, MA, USA) and incubated at $37^{\circ} \mathrm{C}$ in a humidified $5 \% \mathrm{CO}_{2} / 95 \%$ air atmosphere. Following 4 days of incubation, nonadherent cells were removed by replacing the medium. Thereafter, the medium was changed twice a week. At 80\%-90\% confluence, cells were harvested with $0.05 \%$ trypsin-EDTA (Life Technologies, Carlsbad, CA, USA) for 3 minutes at $37^{\circ} \mathrm{C}$. Before the experiments, cells were harvested in the log phase of growth and their viability was determined by $0.4 \%$ Trypan blue exclusion. The cells were used after three to five passages.

\section{Synthesis and physicochemical characterization of the SPIONs}

SPIONs were prepared from iron salt solutions by coprecipitation in alkaline media at $80^{\circ} \mathrm{C}$, according to Massart. ${ }^{31}$ $\mathrm{FeSO}_{4}$ and $\mathrm{FeCl}_{3}$ at an $\mathrm{Fe}^{2+} / \mathrm{Fe}^{3+}$ ratio of 1:2 were dissolved in water with the addition of $\mathrm{CsCl}$. Magnetite precipitation was induced by titration with an $\mathrm{NH}_{4} \mathrm{OH}$ solution in an inert atmosphere under vigorous stirring in a $100 \mathrm{~mL}$ reactor. The precipitate was collected by a permanent magnet. The magnetite suspension in water was treated by ultrasound at $22 \mathrm{kHz}$ for 15 minutes. To prevent sedimentation, low molecular weight dextran (molecular weight: $10 \mathrm{kDa}$; Sigma-Aldrich Co., St Louis, MO, USA) was added to the dispersion during the process of ultrasound application. The prepared stock solutions of nanoparticles were washed and separated into fractions by centrifugation and microfiltration using $0.2 \mu \mathrm{m}$ pore membranes (EMD Millipore, Billerica, MA, USA). The fine fraction of SPIONs was characterized and stored in water at $4^{\circ} \mathrm{C}$ prior to preparation of the conjugates. The Fe content in the suspension was controlled by the ultraviolet absorption of the thiocyanate- $-\mathrm{Fe}^{3+}$ complex at $\lambda=480 \mathrm{~nm}$.

\section{Labeling of the BMSCs with magnetic nanoparticles}

\section{Cell viability and proliferation}

Cells were incubated with phosphate-buffered saline (control) and SPIONs (at an Fe concentration of $150 \mu \mathrm{g} / \mathrm{mL}$ ) for $1,3,12$, and 24 hours in a $\mathrm{CO}_{2}$ incubator. Following incubation, cells were washed and viability was assessed by $0.4 \%$ Trypan blue exclusion. Additionally, the 3-(4,5dimethylthiazol-2-yl)-2,5-diphenyltetrazolium bromide (MTT) assay was used to test the cytotoxicity of the magnetic nanoparticles and cell proliferation. We applied a Vybrant ${ }^{\mathbb{R}}$ MTT Cell Proliferation Assay Kit according to the manufacturer's protocol (Life Technologies).

\section{Confocal microscopy}

Cells were seeded onto glass slides and harvested in $\alpha$-MEM supplemented with $10 \%$ FBS, 2 mM of L-glutamine, 100 units $/ \mathrm{mL}$ of penicillin $\mathrm{G}$, and $100 \mu \mathrm{g} / \mathrm{mL}$ of streptomycin (Life Technologies). For analysis of nanoparticle internalization, cells were incubated with SPIONs $(150 \mu \mathrm{g} / \mathrm{mL})$ for 6 , 12 , and 24 hours. Following co-incubation with nanoparticles, cells were extensively washed and fixed with $4 \%$ paraformaldehyde. The nuclei were stained with 4',6-diamidino2-phenylindole (DAPI). Glasses were mounted in Dako fluorescence mounting medium (Dako North America Inc., Carpinteria, CA, USA). Assessment of the incorporation of magnetic nanoparticles into BMSCs was performed by confocal microscopy. For the analysis of magnetic nanoparticle incorporation, reflected laser scanning was applied. Fluorescent images were captured with a Leica TCS SP5 confocal system, equipped with lasers exciting at $488 \mathrm{~nm}(\mathrm{Ar} / \mathrm{Kr})$ on a Leica DM IRBE microscope (Leica Microsystems, Wetzlar, Germany). For evaluation of the localization of nanoparticles, single Z-planes were analyzed with Leica confocal software (LCS Lite; Leica Microsystems) and ImageJ 1.37 (Wright Cell Imaging Facility, Toronto, ON, Canada). Image presentation, size, and contrast were adjusted with Photoshop 7.0 software (Adobe Systems Incorporated, San Jose, CA, USA).

\section{Seeding the PL-SF scaffolds with BMSCs}

PL-SF scaffolds were co-incubated with BMSCs (PL-SF[+]) $\left(2 \times 10^{6}\right)$ in collagen type I gel $(2 \mathrm{mg} / \mathrm{mL})$ at $37^{\circ} \mathrm{C}$ in a humidified $5 \% \mathrm{CO}_{2} / 95 \%$ air atmosphere for 30 minutes. Following polymerization of collagen gel, scaffolds were harvested in $\alpha$-MEM medium supplemented with $10 \% \mathrm{FBS}, 2 \mathrm{mM}$ of L-glutamine, 100 units/mL of penicillin $\mathrm{G}$ and $100 \mu \mathrm{g} / \mathrm{mL}$ of streptomycin (Life Technologies) in a $\mathrm{CO}_{2}$ incubator for 3-5 days. PL-SF scaffolds filled with collagen gel containing no BMSCs (PL-SF[-]) were used as a control. Following incubation for 24 and 48 hours, cells were recovered from the scaffolds, washed and viability was assessed by $0.4 \%$ Trypan blue exclusion. The MTT assay was used to test the cytotoxicity of the scaffold and cell proliferation. We applied a Vybrant MTT Cell Proliferation Assay Kit according to the manufacturer's protocol (Life Technologies).

\section{Surgical technique}

New Zealand rabbits weighing 3-3.5 kg were obtained from the Rappolovo Laboratory Animal Nursery of the Russian Academy of Medical Sciences (St Petersburg, Russia). Animals were housed in cages under pathogen-free conditions, controlled temperature and humidity, and a 12 hours light-dark 
cycle, with food and water ad libitum. For anesthesia, intravenous injection of a ketamine $(10-50 \mathrm{mg} / \mathrm{kg})$ and xylazine (1-3 $\mathrm{mg} / \mathrm{kg}$ ) mixture was applied. A light sedative agent, fentanyl/ droperidol $(0.2 \mathrm{mg} / \mathrm{kg})$, was administered intramuscularly prior to anesthesia to avoid stress in the rabbit. The bladder wall was dissected and a partial cystectomy $\left(10 \times 10 \mathrm{~mm}^{2}\right)$ was performed for further implantation of the PL-SF scaffold. The graft was placed on the bladder wall defect and sutured with 6.0 Vicryl stitches, then the bladder was filled with normal saline to check leakage from the suture line. The bladder was covered with a perivisceral fat layer to provide vascularization. In the postoperative period all animals were given one intramuscular injection of 300,000 EU of the antibiotic bicillin-3 (benzathine benzylpenicillin) (Sintez, Moscow, Russia) every 3 days (a total of four injections). In this study, the animals were divided into two groups as follows (six animals each): 1) a control group with a PL-SF graft filled with collagen gel and without cells and 2) an experimental group with a PL-SF scaffold seeded with iron-labeled BMSCs. The follow-up period constituted two time points of 8 and 12 weeks, after which three animals from each group were sacrificed and their bladder extracted and analyzed in histological and immunofluorescence assays. Before being euthanized, cystography and urodynamic analysis were performed.

All animal-handing procedures were performed according to the Guide for the Care and Use of Laboratory Animals of the Saint-Petersburg Scientific Research Institute of Phthisiopulmonology, Russian Ministry of Health Care and followed the guidelines of the Animal Welfare Protocol No 25, 10.28. All animal experiments were approved by the ethical committee of the Saint Petersburg Scientific Research Institute of Phthisiopulmonology, Russian Ministry of Health Care.

\section{Functional and EMG study of reconstructed urinary bladder}

The functional activity of the urinary bladder was tested by filling with saline under EMG control. Activity of the intact part of the bladder and the wall reconstructed with scaffold-based mesenchymal stromal cells was monitored synchronously using a disposable subdermal stainless electroencephalogram needle (length $12 \mathrm{~mm}$; diameter $0.40 \mathrm{~mm}$ ) (Viasys, Santa Monica, CA, USA). The detrusor was stimulated by slow filling with $25 \mathrm{~mL}$ of physiological saline at $24^{\circ} \mathrm{C}$. Two pairs of electrodes were placed within the wall of the bladder at both intact and reconstructed parts.

\section{Magnetic resonance imaging}

MRI scans were performed on a $3.0 \mathrm{~T}$ whole-body scanner (Siemens, Munich, Germany). The rabbit position was supine. To obtain axial T2-weighted images we applied a turbo spin-echo sequence (TR 4,800 ms; TE $90 \mathrm{~ms}$; slice thickness $1 \mathrm{~mm}$, FoV $60 \times 100 \mathrm{~mm}^{2}$, and matrix size $256 \times 256$ pixel). For detection of SPION-labeled BMSCs in the PL-SF scaffold, follow-up serial T2*-weighted gradient echo imaging was performed at 4,8 , and 12 weeks.

\section{Histological analysis}

At the designated time point, animals were euthanized by $\mathrm{CO}_{2}$ asphyxiation, bladders were extracted and fixed in $10 \%$ formalin. Paraffin sections of 3-5 mm were stained with hematoxylin and eosin (H\&E) or Van Gieson's stain. The thickness of the urothelium and thickness of the submucous, muscular, and external connective-tissue shell of the bladder were measured by a morphometric study. Additionally, the quantity of microvessels was assessed. All samples were analyzed for infiltration with neutrophils, macrophages, and lymphocytes using a Leica DM LS photo-optical microscope equipped with a Leica DC320 camera.

For the detection of iron-labeled BMSCs in the graft, the extracted samples were embedded in Tissue-Tek ${ }^{\circledR}$ (Sakura Finetek Europe BV, Alphen an den Rijn, the Netherlands) and stored at $-80^{\circ} \mathrm{C}$. Sections $(5-7 \mu \mathrm{m}$ thick) prepared from these blocks were mounted on Superfrost ${ }^{\mathrm{TM}}$ Plus slides (Thermo Fisher Scientific) and used for the detection of cells with magnetic conjugates through confocal microscopy. Sections were additionally stained with DAPI. Fluorescence images were obtained using a Leica TCS SP5 confocal system (Leica Microsystems). SPIONs were detected by reflected laser scanning with laser excitation at $504 \mathrm{~nm}$ (Ar/Kr). Nuclei were detected using a diode laser (405 nm).

\section{Statistical analysis}

One- or two-tailed Student's $t$-tests were used to evaluate the differences between the control and experimental groups. All data were run using Statistica Version 9.2 for Windows (StatSoft, Inc, Tulsa, OK, USA). $P$-values of $<0.05$ were considered statistically significant for all tests.

\section{Results \\ Development of the PL-SF scaffold seeded with iron-labeled BMSCs}

For reconstruction of the bladder wall defect we synthesized bilayered PL-SF scaffolds with a thickness of $2.0 \mathrm{~mm}$ and diameter of $22 \mathrm{~mm}$ (Figure 1A). SEM analysis demonstrated that the first layer of the scaffold consisted of paralleloriented silk fibers and the second outer layer was more compact and consisted of only a poly-L-lactic acid polymer (Figure 1B). The high porosity structure of the inner layer 

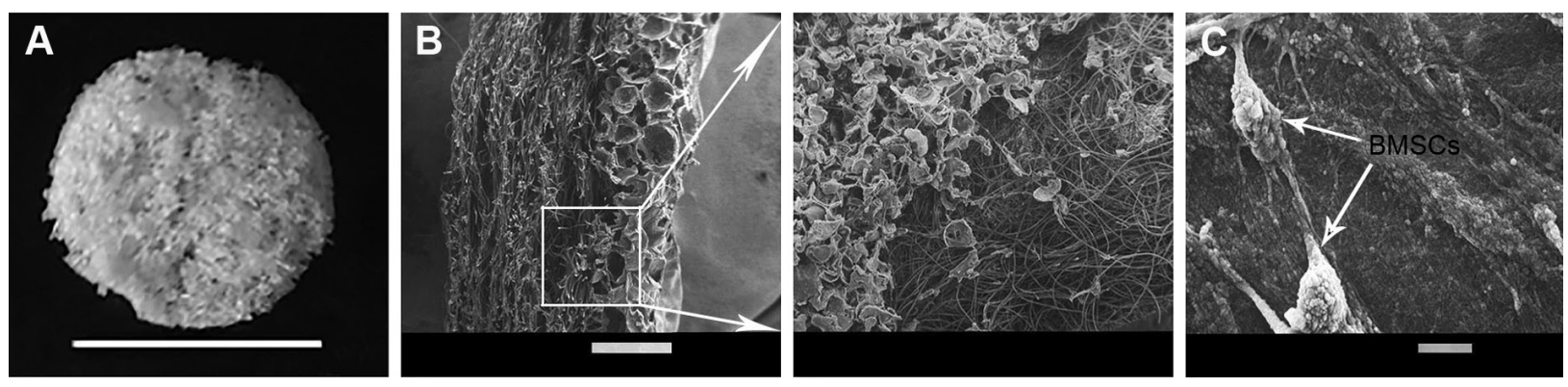

Figure I PL-SF bilayer scaffold.

Notes: (A) Macrophoto of the PL-SF scaffold. Scale bar, I cm. (B) SEM of the cross section of the acellular PL-SF scaffold. Scale bar, I,000 $\mu$ m. (C) SEM of the PL-SF scaffold co-incubated with BMSCs for $24 \mathrm{~h}$. Scale bar, $10 \mu \mathrm{m}$.

Abbreviations: BMSCs, bone marrow stromal cells; PL-SF, poly-L-lactide/silk fibroin; SEM, scanning electron microscopy.

contributes to cell migration inside the membrane and the free flow of nutrients in the depth of the scaffold. Poly-Llactic acids of the outer hydrophobic layer consisted of a porous structure (pore diameter 250-300 $\mu \mathrm{m}$ ) with a system of interconnected spherical pores. Deformation-strength properties of silk fibers before and after treatment were investigated using an Instron 5,943 universal tensile machine (Instron, High Wycombe, UK). On the basis of the stretching chart, strength ( $\sigma \mathrm{p}, \mathrm{MPa})$, elongation at break ( $(\varepsilon p, \%)$, and modulus of rigidity (E0, GPa) for the two-layer scaffold were determined. The strength of the obtained sample was $0.00780 \mathrm{MPa}$, elongation at break $19.14004 \%$, and modulus of rigidity $0.55649 \mathrm{GPa}$. Following seeding of the scaffold with BMSCs, SEM images clearly demonstrated that stem cells had normal morphology on the surface of the graft and formed multilayers throughout the bilayer scaffold (Figure 1C). The cytotoxicity assays clearly demonstrated that there was no toxicity of the scaffold after co-incubation with BMSCs for 48 hours. Prior to labeling the stem cells with superparamagnetic nanoparticles, we investigated the toxic effects of SPIONs on the cells, and analyzed BMSC proliferative activity. We did not observe any influence of the nanoparticles on the viability of cells at a concentration of $150 \mu \mathrm{g} / \mathrm{mL}$ and co-incubation for 24 hours. Viability, according to the Trypan blue exclusion assay, did not differ for all periods of incubation (ie, 1, 3, 12, and 24 hours) with SPIONs and was not different from the control cells $(P<0.05)$. The standard MTT assay did not reveal any influence of SPIONs on cell proliferation, which did not differ from the control (Figure S1). Confocal microscopy imaging of the BMSCs incubated with nanoparticles demonstrated that after 6 hours there was internalization of the SPIONs into the stem cells (Figure 2). Nanoparticles presented as red dots in the cytoplasm of the cells surrounding but not penetrating the nucleus. The highest level of SPION accumulation was observed after 24 hours of incubation (Figure 2). For seeding the PL-SF

\section{SPIONs}
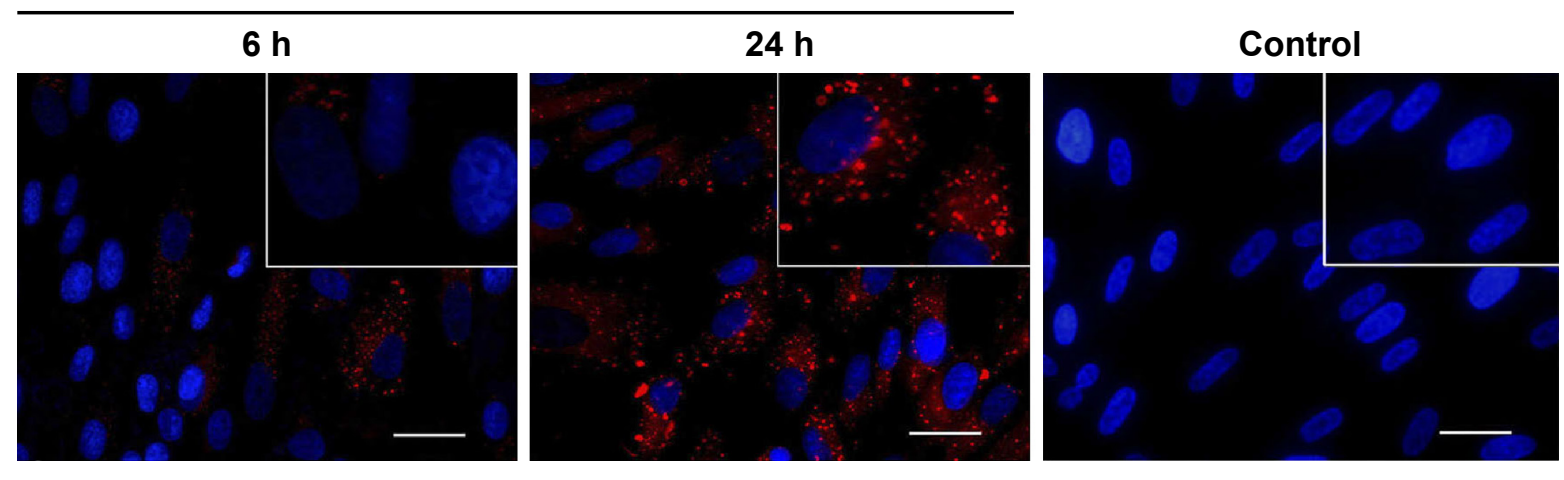

\section{DAPI Nanoparticles}

Figure 2 Assessment of SPION internalization by BMSCs.

Notes: Confocal microscopy images of BMSCs co-incubated with SPIONs ( $150 \mu \mathrm{g} / \mathrm{mL})$ for 6 and 24 h. Nuclei were stained with DAPI (blue) and detected using a diode laser $(405 \mathrm{~nm}$ ). Magnetic nanoparticles were detected by reflected laser scanning at $488 \mathrm{~nm}$ (red). Scale bar, $100 \mu \mathrm{m}$. Inset pictures show magnified images of the control and cells treated with SPIONs. Magnification, $\times 40$.

Abbreviations: BMSCs, bone marrow stromal cells; DAPI, 4',6-diamidino-2-phenylindole; SPIONs, superparamagnetic iron oxide nanoparticles; h, hours. 

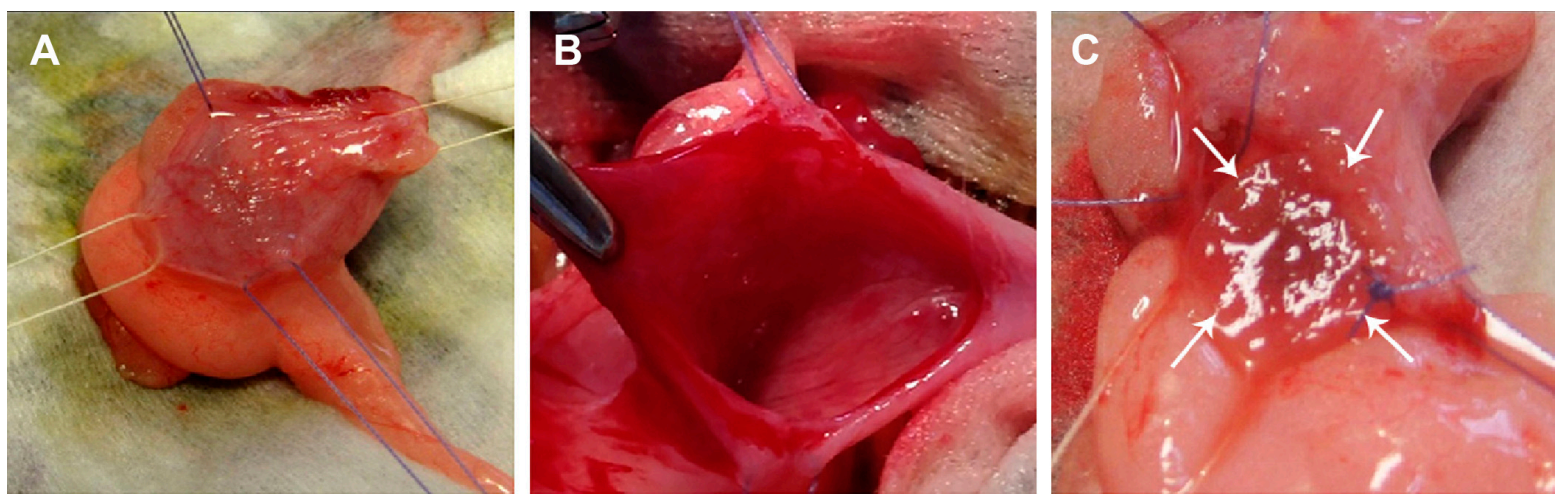

Figure 3 Partial bladder wall cystectomy.

Notes: (A) Mobilization of the bladder wall. (B) Partial cystectomy. The size of the defect in the wall was $10 \times 10 \mathrm{~mm}^{2}$. (C) Reconstruction of the bladder wall with PL-SF scaffold seeded with BMSCs. The scaffold is indicated by white solid arrows.

Abbreviations: BMSCs, bone marrow stromal cells; PL-SF, poly-L-lactide/silk fibroin.

scaffold with iron-labeled cells, the latter were embedded into a gel based on type I collagen after co-incubation with SPIONs for 24 hours (at an Fe concentration of $150 \mu \mathrm{g} / \mathrm{mL}$ ). PL-SF scaffolds were co-incubated with BMSCs $\left(2 \times 10^{6}\right)$ in collagen type I gel for 30 minutes. Following polymerization of collagen gel, scaffolds were incubated in a $\mathrm{CO}_{2}$ incubator for 3-5 days.

\section{Reconstruction of the bladder wall defect with the PL-SF graft}

Following bladder exposure, partial cystectomy was performed in 12 rabbits with a surface defect of $\sim 1.0 \mathrm{~cm}^{2}$ (see Video S1, Figure 3). The PL-SF acellular graft or PL-SF seeded with iron-labeled BMSCs was sutured as a patch onto the bladder wall defect with 6.0 Vicryl sutures (Figure 3C). A piece of perivisceral fat was wrapped over the graft. A catheter was inserted to provide bladder drainage for 3 days after the operation. Following animal sacrifice we observed efficient biointegration of the PL-SF $(+)$ scaffold with bladder tissues (Figure 4A and $\mathrm{B}$ ) while complete rejection of the PL-SF(-) scaffold was observed in the bladder cavity in two out of six animals in the control group (Figure 4C and D).

During the follow-up period of 12 weeks, no sign of infection, fistulae, stone formation, or upper urinary tract complications were observed in any of the animals from the experimental group in macroscopic evaluations. To assess PL-SF scaffold biointegration in the postoperative period, we performed MRI of the bladder 4, 8, and 12 weeks after implantation using a 3.0 T clinical MRI scanner (Siemens). For MRI detection of the graft inside the bladder wall, BMSCs were labeled with SPIONs that could be analyzed on T2-weighted scans as a "dark" contrast negative zone (Figure 5). Following implantation of the PL-SF(+) scaffold we observed the presence of a dark artifact in the bladder wall for the whole follow-up period of 8 weeks (Figure 5). When we analyzed the animals in the control group, we observed rejection of the graft into the lumen of the bladder in two out of six animals.

Subsequent analysis of bladder activity using EMG also proved the functional properties of the implanted scaffold (Figure 6). Thus, bladder refilling with saline solution clearly demonstrated that the reconstructed bladder could accept the same volume of solution as the intact bladder (20-24 mL) (Figure 4E and F). The EMG monitoring of the bladder wall performed during the refilling tests showed electrical activity during induced voiding in both intact and reconstructed parts of the detrusor. Following refilling in 7-10 seconds we observed low-amplitude EMG activity in the intact part of the detrusor that was also presented in the reconstructed bladder wall. EMG activity in both parts of the detrusor preceded and accompanied the voiding with steady-state magnitude (Figure 6B). As compared to the intact part of the bladder wall, the observed EMG activity in the operated part of the bladder had noticeably lower magnitude and duration (Figure 6B). The excitability of muscle fibers in the reconstructed part of the detrusor before and during voiding indicated the functional activity and biointegration of the scaffold.

\section{The PL-SF graft seeded with stem cells increases bladder regeneration}

To verify the effectiveness of the reconstructed bladder, histological sections were assessed by light microscopy. Bladder samples with implanted grafts were analyzed in weeks 8 and 12 following the operation. Bladder tissue of the intact rabbit was used as a control (Figure 7). In all animals 

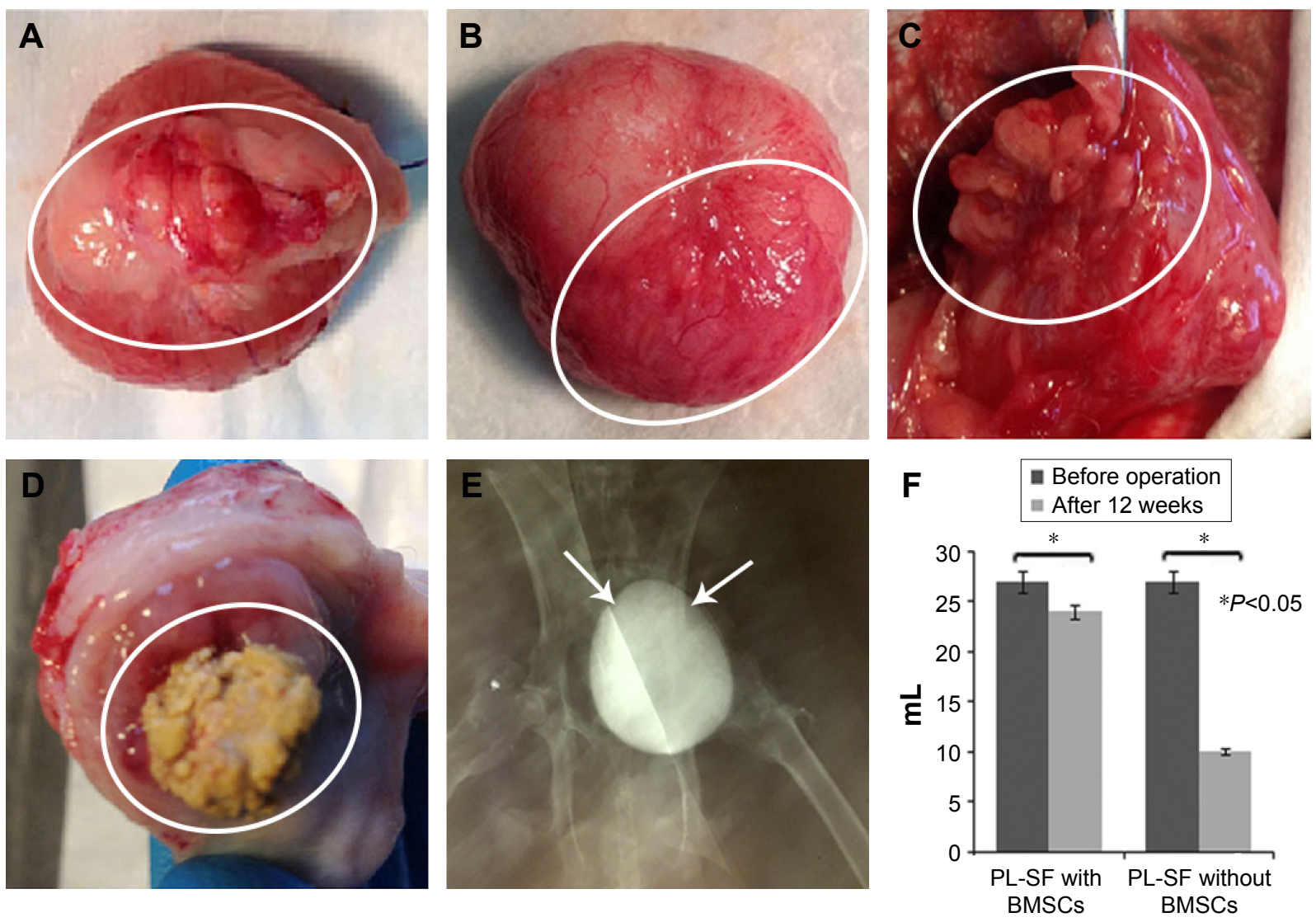

Figure 4 Reconstruction of the bladder wall defect with the bilayer PL-SF scaffold.

Notes: (A) External and (B) internal surfaces of the bladder following augmentation with the PL-SF scaffold seeded with BMSCs. The follow-up period was I 2 weeks. The scaffold is indicated by a white solid ellipse. (C) External and (D) and internal surfaces of the bladder reconstructed with acellular PL-SF scaffold. At the end of the follow-up period, rejection of the scaffold (D) into the bladder lumen was observed. (E) Cystography of the bladder. The bladder is indicated by white solid arrows. (F) Bladder volume capacity following implantation of the PL-SF scaffolds.

Abbreviations: BMSCs, bone marrow stromal cells; PL-SF, poly-L-lactide/silk fibroin.

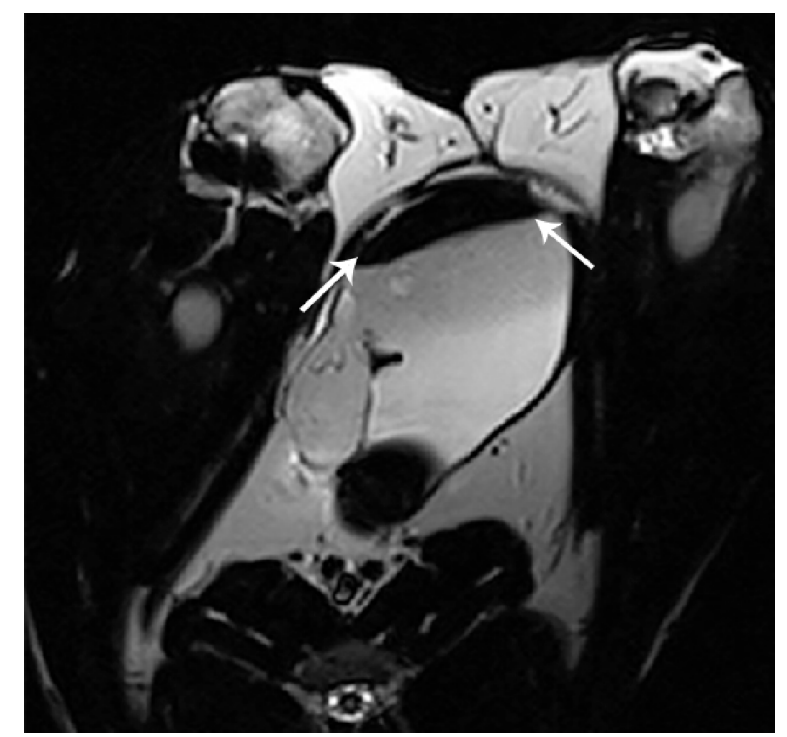

Figure 5 MRI of the PL-SF scaffold seeded with iron-labeled BMSCs after 8 weeks of implantation.

Note: The scaffold is indicated by white solid arrows.

Abbreviations: BMSCs, bone marrow stromal cells; MRI, magnetic resonance imaging; PL-SF, poly-L-lactide/silk fibroin. at the site of implantation of the scaffold, we observed complete regeneration of the bladder wall including four layers: mucosa, submucosa, muscular coat, and adventitia (Figure 7, Table 1). The scaffold material could not be visualized in the H\&E staining due to complete degradation of the PL-SF material. In the intact control animals, the mucous membrane was represented by transitional epithelium and the lamina propria, which consisted of collagen and elastic fibers. The thickness of the transitional epithelium was $91.7 \pm 5.9 \mu \mathrm{m}$, and the thickness of the mucous layer was $22.5 \pm 1.1 \mu \mathrm{m}$ (Table 1 ). Submucosal tissue contained loose connective tissue with a thickness of $325.0 \pm 44.4 \mathrm{~mm}$. Microcirculatory vessels $\left(1 \mathrm{~mm}^{2}\right)$ were determined as $3.0 \pm 0.01$ with the diameter of the lumen $52.5 \pm 9.8 \mu \mathrm{m}$. The muscular layer was represented by three layers of smooth muscle fibers with their longitudinal course in the inner and outer layers and circular course in the middle layer with thickness of $1,700.0 \pm 108.4 \mu \mathrm{m}$. The adventitia was also represented by loose fibrous connective tissue, the thickness of which amounted to $27.5 \pm 5.0 \mu \mathrm{m}$. 
A

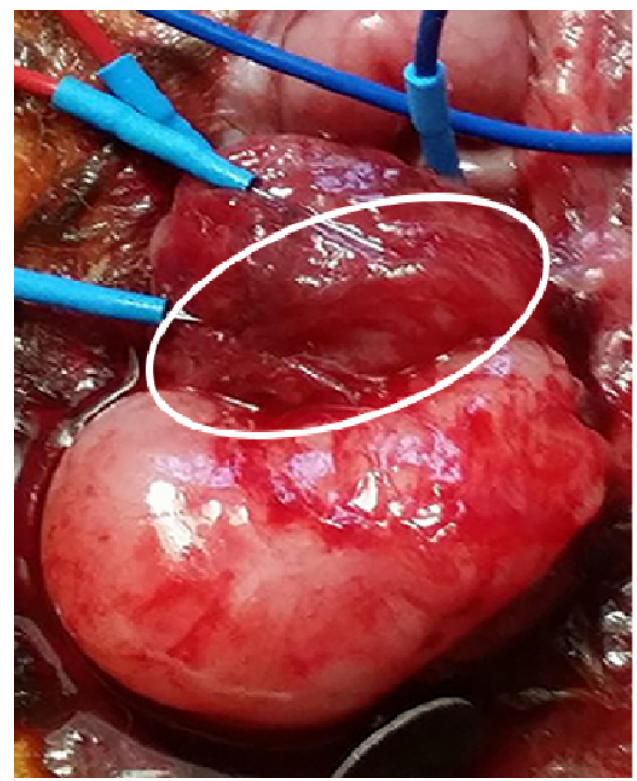

\section{B}

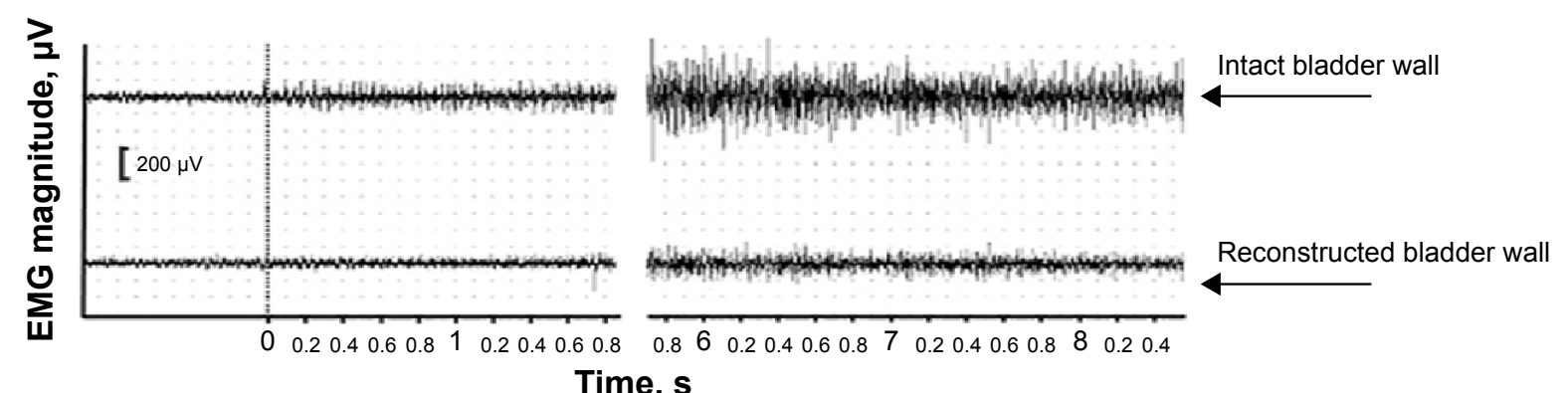

Time, $\mathbf{s}$

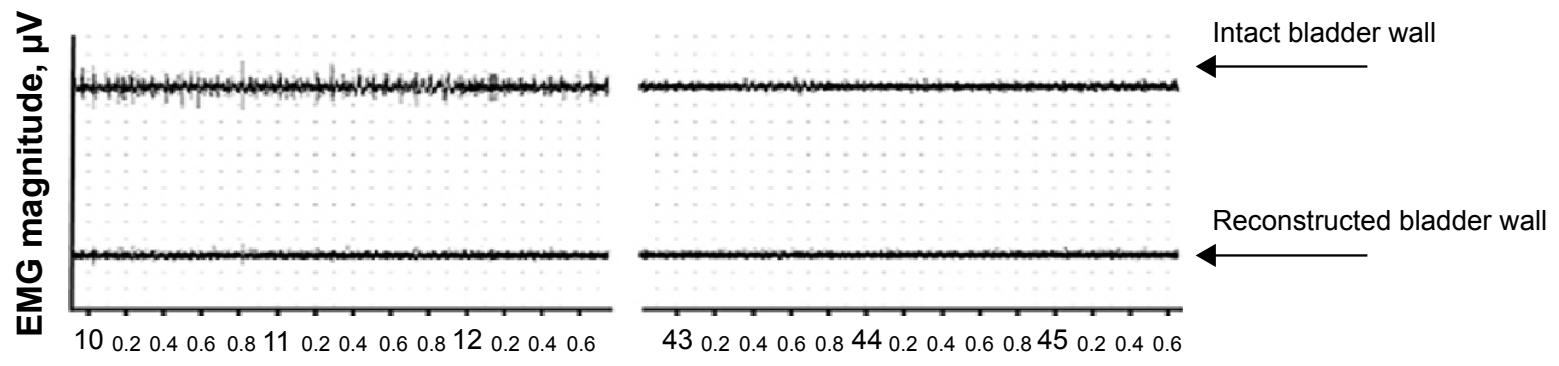

Time, $\mathbf{s}$

Figure 6 Electromyography of the bladder wall following reconstruction.

Notes: (A) Macrophoto of the bladder wall with implanted PL-SF scaffold seeded with BMSCs and electroencephalogram electrodes. The scaffold is indicated by a white solid ellipse. (B) Electromyogram test of the intact and reconstructed bladder wall.

Abbreviations: BMSCs, bone marrow stromal cells; PL-SF, poly-L-lactide/silk fibroin.

Fibrosis and inflammatory infiltration in the bladder wall were not determined. In the experimental group, when a PL-SF graft seeded with BMSCs was applied, the bladder wall consisted of the mucosa, submucosa, muscular, and adventitia layers (Figure 7). The adventitia was substituted with serous membrane. The mucous membrane was epithelized and presented as a transitional epithelium layer with increased content of collagen fibers (stained by Van Gieson's stain). The thickness of the transitional epithelium was not significantly different from that of the control group and was $90.8 \pm 6.0 \mu \mathrm{m}$. There was a significant increase of the lamina propria of the mucous layer to $31.7 \pm 3.1 \mu \mathrm{m}$ (Table 1). The submucous membrane was enlarged due to edema $(1,108.3 \pm 61.8 \mu \mathrm{m})$. The number of $1 \mathrm{~mm}^{2}$ microcirculatory vessels was also increased $-8.0 \pm 0.4 \mu \mathrm{m}$. The diameter of the vessels was also increased and was $95.8 \pm 14.1 \mu \mathrm{m}$. In the muscular layer we observed edema and formation of loose fibrous connective tissue between the circular and longitudinal layers. The thickness of the swelling was significantly increased and was $3,416.7 \pm 156.5 \mu \mathrm{m}$; the adventitia was $283.3 \pm 42.7 \mu \mathrm{m}$. Following partial resection of the bladder wall, the muscular tissue was replaced by connective tissue 


\section{Scaffold seeded with BMSCs}
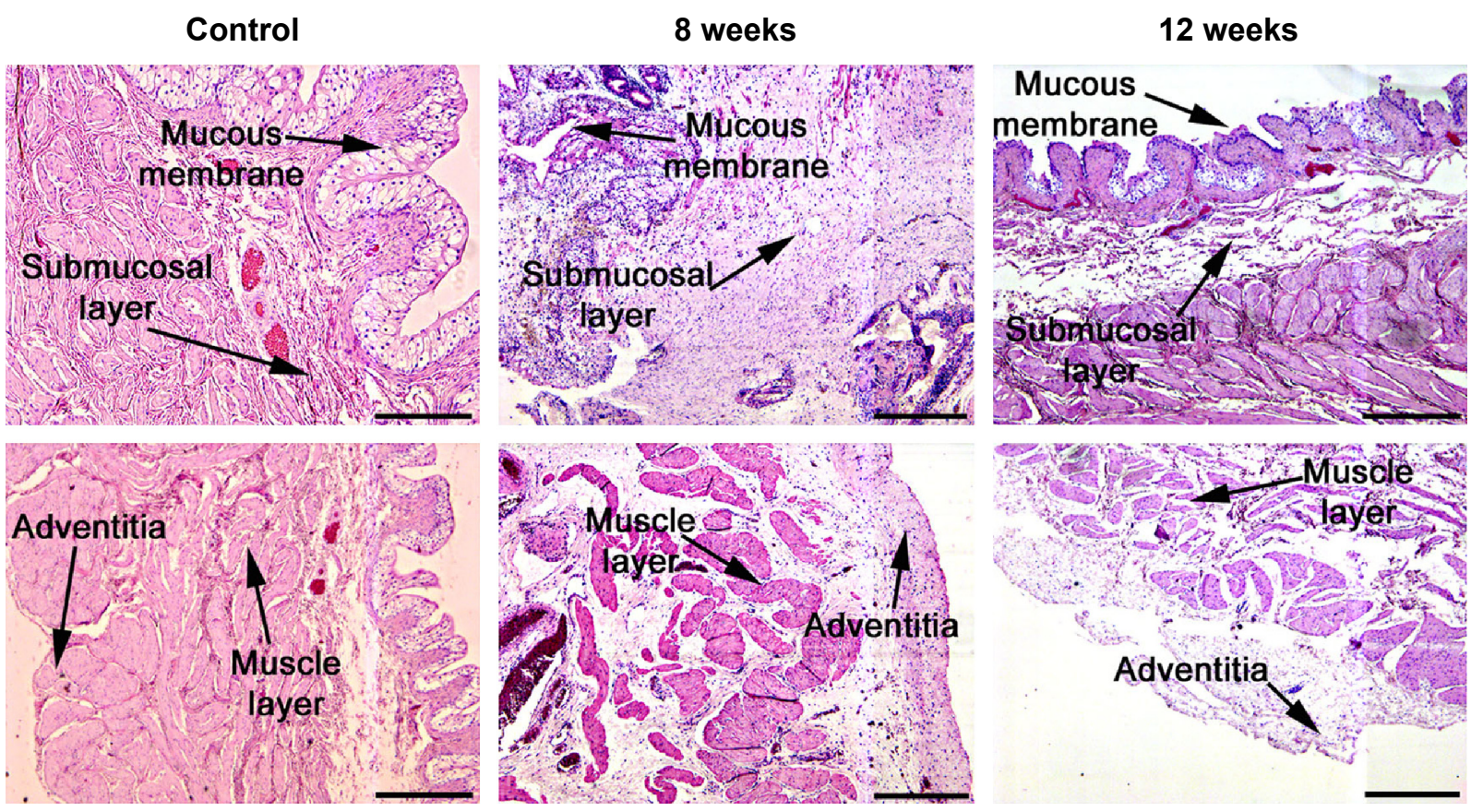

Figure 7 Histological sections of the reconstructed bladder wall stained with H\&E. Notes: The intact bladder wall was used as control. Scale bar, $200 \mu \mathrm{m}$.

Abbreviations: BMSCs, bone marrow stromal cells; H\&E, hematoxylin and eosin.

with lymphocytic infiltration and granulomas with giant multinucleated cells. At the end of the follow-up period of 12 weeks the thickness of the transitional epithelium was not significantly changed and was $88.3 \pm 5.3 \mu \mathrm{m}$. We observed a significant increase of lamina propria thickness compared to intact rabbits $-62.5 \pm 5.1 \mu \mathrm{m}$ (Table 1). The submucous membrane was moderately increased due to edema $(416.7 \pm 11.8 \mu \mathrm{m})$; the number of vessels did not differ from the control group though there was enlargement of the diameter $-85.0 \pm 3.5 \mu \mathrm{m}$. We observed slight edema in the muscular layer with increased content of collagen fibers. The adventitia contained a high content of connective tissue with a thickness of $83.8 \pm 8.1 \mu \mathrm{m}$. In the control group, only four from six animals were histologically assessed due to rejection of the graft. When an acellular PL-SF graft was applied, we observed lymphocytic infiltration at the implantation site that was not detectable in the experimental group (Figure S2).

To reveal iron-labeled cells at the implantation site, confocal microscopy of bladder cryosections was performed using reflected laser scanning. The cells were detected in different morphological structures of the bladder including the epithelial layer (Figure 8A) and in the muscular wall (Figure 8B). We did not detect any iron-labeled cells in native bladder wall tissues (Figure 8C).

Table I Morphometric analysis of the reconstructed bladder wall

\begin{tabular}{|c|c|c|c|}
\hline Parameter/group & $\begin{array}{l}\text { Control } \\
\text { intact rabbit }\end{array}$ & $\begin{array}{l}\text { Reconstructed bladder } \\
\text { wall after } 8 \text { weeks }\end{array}$ & $\begin{array}{l}\text { Reconstructed bladder } \\
\text { wall after } 12 \text { weeks }\end{array}$ \\
\hline Urothelium thickness, $\mu \mathrm{m}$ & $91.7 \pm 5.9$ & $90.8 \pm 6.0$ & $88.3 \pm 5.3$ \\
\hline Lamina propria thickness, $\mu \mathrm{m}$ & $22.5 \pm 1.1$ & $31.7 \pm 3.1^{*}$ & $62.5 \pm 5.1^{*}$ \\
\hline Submucosal layer thickness, $\mu \mathrm{m}$ & $325.0 \pm 44.4$ & $\mathrm{I}, 108.3 \pm 6 \mathrm{I} .8^{*}$ & $416.7 \pm 11.8^{*}$ \\
\hline I mm² microvessel quantity & $3.0 \pm 0.01$ & $8.0 \pm 0.4^{*}$ & $4.0 \pm 0.0$ \\
\hline \multicolumn{4}{|l|}{ in the submucosal layer } \\
\hline \multicolumn{3}{|l|}{ in the submucosal layer, $\mu \mathrm{m}$} & $85.0 \pm 3.5^{*}$ \\
\hline Muscular layer thickness, $\mu \mathrm{m}$ & $\mathrm{I}, 700.0 \pm 108.4$ & $3,416.7 \pm 156.5^{*}$ & $\mid, 583.3 \pm 31.3$ \\
\hline Adventitia thickness, $\mu \mathrm{m}$ & $27.5 \pm 5.0$ & $283.3 \pm 42.7^{*}$ & $83.8 \pm 8 . I^{*}$ \\
\hline
\end{tabular}

Notes: $* P<0.05$. Data shown as mean \pm standard deviation. 

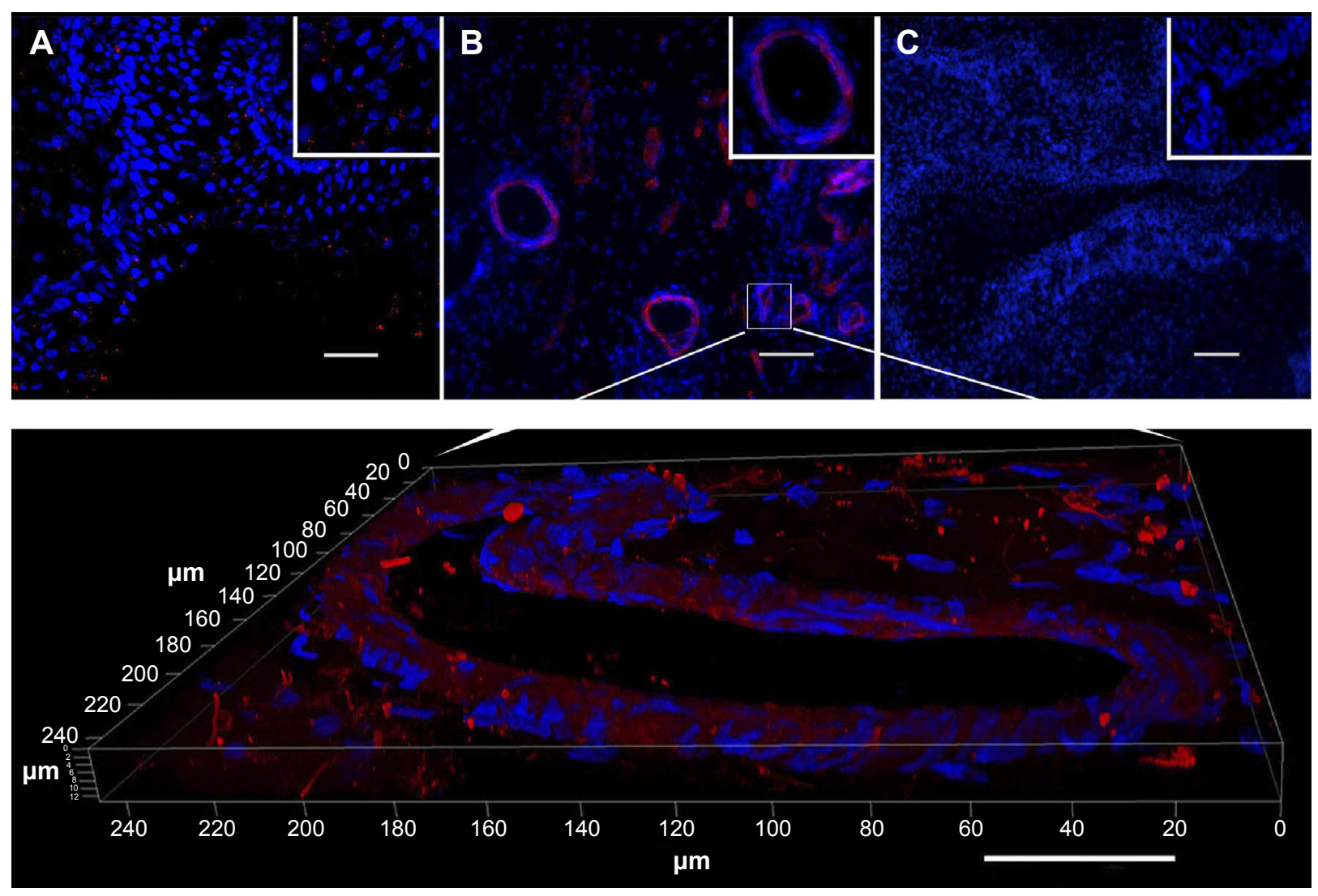

\section{DAPI Nanoparticles}

Figure 8 Cryosections of the bladder wall with implanted PL-SF scaffold.

Notes: Confocal microscopy of the PL-SF scaffold seeded with SPION-labeled BMSCs. The follow-up period was 12 weeks. Nanoparticles were detected using reflected laser scanning in the mucosal and submucosal layers. (A) Muscular layer. Scale bar, $50 \mu \mathrm{m}$. (B) Nuclei were stained with DAPI (blue) and detected using a diode laser (405 $\mathrm{nm}$ ). Scale bar, $100 \mu \mathrm{m}$. Iron-labeled cells were detected in all layers of the bladder. (C) Confocal microscopy of the control intact bladder wall. Scale bar, I00 $\mu \mathrm{m}$. Inset pictures show magnified images of the non-labeled and iron-labeled cells. Magnification, $\times 20$.

Abbreviations: BMSCs, bone marrow stromal cells; DAPI, 4',6-diamidino-2-phenylindole; PL-SF, poly-L-lactide/silk fibroin; SPION, superparamagnetic iron oxide nanoparticles.

\section{Discussion}

Bladder augmentation or partial substitution is one of the main surgical challenges in urology that is required for different clinical conditions including contracted bladder, tumors, bladder fibrosis, and neurogenic bladder. In previous studies, application of gastrointestinal decellularized segments or alloplastic materials did not lead to satisfying results. ${ }^{32}$ One of the possible strategies to increase the biocompatibility of the graft and reduce complications could be based on the seeding of the implant with cells. ${ }^{33}$ To date, several cell sources have been suggested including pluripotent stem cells, human umbilical mesenchymal stem cells, urothelial, and smooth muscle cells. ${ }^{34-37}$ In our studies for enhancing the integrative properties of grafts, we applied allogenic BMSCs which have immunosuppressive action ${ }^{17-19}$ and are able to differentiate in different directions. ${ }^{20-22}$

The data obtained clearly demonstrate the efficacy and safety of a two-layer scaffold (PL-SF) seeded with allogenic
BMSCs in the reconstruction of the bladder wall in a model of partial cystectomy in rabbits. Thus, we did not observe rejection of the cell-seeded implant in any operated animals in comparison to the control group. Furthermore, application of PL-SF $(+)$ grafts resulted in full-thickness bladder regeneration (including urothelium, smooth muscle, and vessels; Figure 7). Presumably, seeded BMSCs not only stimulated ingrowth of the tissues into the graft but also differentiated into other types of cells in situ. Thus, in the study by Bouhout et al it was demonstrated that a graft seeded with bladder mesenchymal cells, when exposed to urine, produced urothelium with physiologic pseudostratification and cellular polarity. ${ }^{38}$

For tracking BMSCs in the implanted graft in vivo, the cells were labeled with SPIONs that, due to MRI negative contrast-enhancing properties, could be applied for live imaging. The cytotoxicity assays clearly demonstrated the absence of toxic effects of the nanoparticles toward BMSCs according to Trypan blue or MTT assays. These results correspond to 
our earlier published data in which SPIONs were applied for diagnostic purposes..$^{39,40}$ In the work by Yun and Ja it was also shown that loading of MSCs with SPIONs did not influence the functional activity of the cells which underwent normal chondrogenic, adipogenic, and osteogenic differentiation. ${ }^{41}$ PL-SF grafts seeded with iron-labeled BMSCs were visualized as hypotensive zones in the T2-weighted images during the whole follow-up period of 12 weeks (Figure 5). Previously, Lee et al reported that SPION-labeled MSCs could be tracked by MRI in the bladder. ${ }^{42}$ Intriguingly, we observed the presence of labeled BMSCs only in the graft, which might indicate that introduced cells usually stay in the place of implantation without migration into other zones. Subsequent confocal microscopy of bladder cryosections confirmed the presence of the nanoparticle-labeled cells throughout all layers of the wall without any labeled cells in native bladder tissues (Figure 8). Similar data were obtained by other groups when SPION-labeled stem cells were applied. ${ }^{41,43}$

In our study, we applied BMSCs, though combination with other methods might be beneficial in bladder repair. Another possible approach to stimulate bladder regeneration in vivo could be based on application of various agents (eg, cytokines, growth factors) that promote cellular ingrowth from the native bladder wall. ${ }^{44-46}$ Thus, in the recently published study by Xiong et al the authors introduced vascular endothelial growth factor-loaded poly(lactic- $\mathrm{co}$-glycolic acid) nanoparticles for long-term sustained release in bladder acellular matrix allografts in a swine model. ${ }^{44}$ Implantation of this scaffold resulted in increased angiogenesis that reduced contracture during bladder regeneration. ${ }^{44}$

\section{Conclusion}

Application of a bilayer PL-SF scaffold seeded with BMSCs was effective for bladder wall reconstruction in vivo. There was efficient functional regeneration of the bladder proved by histological analysis in a partial cystectomy rabbit model. The proposed method of cystoplasty might be beneficial in regenerative urology for the repair of the bladder wall.

\section{Acknowledgments}

This study was supported by a grant from the Russian Science Foundation (No 14-50-00068) and with financial support from the Federal Agency of Scientific Organizations (Russia). The authors are grateful to Marina Parr, Liudmila Yakovleva, Yaroslav Marchenko, and Boris Nikolaev for synthesis of the magnetic nanoparticles, Olga Genbach for assistance in animal experiments and Yuliya Idrisova for analysis of scaffold properties.

\section{Disclosure}

The authors report no conflicts of interest in this work.

\section{References}

1. Biers S, Venn S, Greenwell T. The past, present and future of augmentation cystoplasty. BJU Int. 2012;109(9):1280-1293.

2. McDouglas W. Metabolic complications of urinary intestinal diversion. J Urol. 1992;147(5):1199-1208.

3. Popov B, Zaichik A, Budko M, et al. [Model to study in vivo transdifferentiation of somatic cells into urothelium]. Tsitologiia. 2010;4(6): 511-519. Russian.

4. Popov B, Zaichik A, Budko M, et al. [Epithelial cells transdifferentiation into bladder urothelium in experiments in vivo]. Tsitologiia. 2011;5(4): 358-365. Russian.

5. Oberpenning F, Meng J, Yoo JJ, Atala A. De novo reconstitution of a functional mammalian urinary bladder by tissue engineering. Nat Biotechnol. 1999;17(2):149-155.

6. Atala A. Tissue engineering of human bladder. Br Med Bull. 2011;97: 81-104.

7. Figueiredo AA, Lucon AM. Urogenital tuberculosis: update and review of 8961 cases from the world literature. Rev Urol. 2008;10(3): 207-217.

8. Yoo J, Meng J, Oberpenning F, Atala A. Bladder augmentation using allogenic bladder submucosa seeded with cells. Urology. 1998;51(2): 221-225.

9. Zhang Y, Kropp B, Moore P, et al. Coculture of bladder urothelial and smooth muscle cells on small intestinal submucosa: potential applications for tissue engineering technology. J Urol. 2000;164(3 Pt 2):928-935.

10. Brehmer B, Rohrmann D, Becker C, Rau G, Jakse G. Different types of scaffolds for reconstruction of the urinary tract by tissue engineering. Urol Int. 2007;78(1):23-29.

11. Mauney J, Cannon G, Lovett M, et al. Evaluation of gel spun silk-based biomaterials in a murine model of bladder augmentation. Biomaterials. 2011;32(3):808-818.

12. Kim U, Park J, Kim H, Wada M, Kaplan D. Three-dimensional aqueous-derived biomaterial scaffolds from silk fibroin. Biomaterials. 2005;26(5):2775-2785.

13. Shved Yu, Kukhareva L, Zorin I, Pinaev GP. Elaboration of biodegradable polymer substrate for cultivation of human dermal fibroblasts. Tsitologiia. 2006;48(2):161-168.

14. Ikada Y, Tsuji H. Biodegradable polyesters for medical and ecological applications. Macromol Rapid Commun. 2000;21(3):117-132.

15. Woo L, Tanaka S, Anumanthan G, et al. Mesenchymal stem cell recruitment and improved bladder function after bladder outlet obstruction: preliminary data. J Urol. 2011;185(3):1132-1138.

16. Tian H, Bharadwaj S, Liu Y, et al. Myogenic differentiation of human bone marrow mesenchymal stem cells on a 3D nano fibrous scaffold for bladder tissue engineering. Biomaterials. 2010;31(5):870-877.

17. Crop M, Baan C, Korevaar S, et al . Donor-derived mesenchymal stem cells suppress alloreactivity of kidney transplant patients. Transplantation. 2009;87(6):896-906.

18. Shang-Xue Y, Xiao-Mei D, Wei W. A big step forward in the treatment of refractory systemic lupus erythematosus: allogenic mesenchymal stem cell transplantation. Acta Pharmacol Sin. 2013;34(4):453-454.

19. Casey A, Dirks F, Liang O, et al. Bone marrow-derived multipotent stromal cells attenuate inflammation in obliterative airway disease in mouse tracheal allografts. Stem Cells Int. 2014;2014:468927.

20. Woodbury D, Schwarz E, Prockop D, Black I. Adult rat and human bone marrow stromal cell differentiate into neurons. J Neurosci Res. 2000; 61(4):364-370.

21. Krampera M, Marconi S, Pasini A, et al. Induction of neural-like differentiation in human mesenchymal stem cells derived from bone marrow, fat, spleen and thymus. Bone. 2007;40(2):382-390.

22. Sato Y, Araki H, Kato J, et al. Human mesenchymal stem cells xenografted directly to rat liver are differentiated into human hepatocytes without fusion. Blood. 2005;106(2):756-763. 
23. Anumanthan G, Makari J, Honea L, et al. Directed differentiation of bone marrow derived mesenchymal stem cells into bladder urothelium. J Urol. 2008;180(Suppl 4):1778-1783.

24. Ning J, Li C, Li H, Chang J. Bone marrow mesenchymal stem cells differentiate into urothelial cells and implications for reconstructing urinary bladder mucosa. Cytotechnology. 2011;63(5):531-539.

25. Zhang D, Qin D, Wie G, Zhang Y. Urothelial differentiation of mesenchymal stem cells for potential application in urinary tract tissue regeneration. J Sci Appl Biomed. 2014;2(3):20-25.

26. Cheon J, Lee JH. Synergistically integrated nanoparticles as multimodal probes for nanobiotechnology. Acc Chem Res. 2008;41(12): $1630-1640$.

27. Di Marco M, Sadun C, Port M, Guilbert I, Couvreur P, Dubernet C. Physicochemical characterization of ultrasmall superparamagnetic iron oxide particles (USPIO) for biomedical application as MRI contrast agents. Int J Nanomedicine. 2007;2(4):609-622.

28. Ramos-Gomez M, Martinez-Serrano A. Tracking of iron-labeled human neural stem cells by magnetic resonance imaging in cell replacement therapy for Parkinson's disease. Neural Regen Res. 2016;11(1): 49-52.

29. Kim JH, Lee HJ, Song YS. Tracking transplanted stem cells using magnetic resonance imaging and the nanoparticle labeling method in urology. Biomed Res Int. 2015;2015:231805.

30. Cromer Berman SM, Walczak P, Bulte JW. Tracking stem cells using magnetic nanoparticles. Wiley Interdiscip Rev Nanomed Nanobiotechnol. 2011;3(4):343-355.

31. Massart R. Preparation of aqueous magnetic liquids in alkaline and acidic media. IEEE Trans Magn. 1981;17(2):1247-1248.

32. Gleeson M, Griffith D. The use of alloplastic biomaterials in bladder substitution. J Urol. 1992;148(5):1377-1382.

33. Zhang Y, Dominic F, Earl Y, Lin HK, Kropp BP. Challenges in a larger bladder replacement with cell-seeded and unseeded small intestinal submucosa grafts in a subtotal cystectomy model. BJU Int. 2006;98(5):1100-1105.

34. Joseph D, Borer J, De Filippo R, Hodges SJ, McLorie GA. Autologous cell seeded biodegradable scaffold for augmentation cystoplasty: phase II study in children and adolescents with spina bifida. J Urol. 2014;191(5):1389-1395.

35. Atala A, Bauer S, Soker S, Yoo J, Retik A. Tissue-engineered autologous bladders for patients needing cystoplasty. Lancet. 2006; 367(9518):1241-1246.
36. Osborn S, Kurzrock E. Production of urothelium from pluripotent stem cells for regenerative applications. Curr Urol Rep. 2015;15(1):466.

37. Yuan H, Zhuang Y, Xiong J, et al. Human umbilical mesenchymal stem cells-seeded bladder acellular matrix grafts for reconstruction of bladder defects in a canine model. PLoS One. 2013;8(11):e80959.

38. Bouhout S, Goulet F, Bolduc S. A novel and faster method to obtain a differentiated 3-dimensional tissue engineered bladder. J Urol. 2015;194(3):834-841.

39. Shevtsov M, Nikolaev B, Ryzhov V, et al. Detection of experimental myocardium infarction in rats by MRI using heat shock protein 70 conjugated superparamagnetic iron oxide nanoparticle. Nanomedicine. 2016;12(3):611-621.

40. Shevtsov M, Nikolaev B, Ryzhov V, et al. Ionizing radiation improves glioma-specific targeting of superparamagnetic iron oxide nanoparticles conjugated with cmHsp70.1 monoclonal antibodies (SPIONcmHsp70.1). Nanoscale. 2015;7(48):20652-20664.

41. Yun S, Ja H. Monitoring transplanted human mesenchymal stem cells in rat and rabbit bladders using molecular magnetic resonance imaging. Neurourol Urodyn. 2007;26(4):584-593.

42. Lee H, An J, Doo S, et al. Improvement in spinal cord injury-induced bladder fibrosis using mesenchymal stem cell transplantation into the bladder wall. Cell Transplantat. 2015;24(7):1253-1263.

43. Geburek F, Mundle K, Conrad S, et al. Tracking of autologous adipose tissue-derived mesenchymal stromal cells with in vivo magnetic resonance imaging and histology after intralesional treatment of artificial equine tendon lesions - a pilot study. Stem Cell Res Ther. 2016;7(1):21.

44. Xiong Q, Lin H, Hua X, et al. A nanomedicine approach to effectively inhibit contracture during bladder acellular matrix allograft-induced bladder regeneration by sustained delivery of vascular endothelial growth factor. Tissue Eng Part A. 2015;21(1-2):45-52.

45. Jiang $X$, Lin $H$, Jiang $D$, et al. Co-delivery of VEGF and bFGF via a PLGA nanoparticle-modified BAM for effective contracture inhibition of regenerated bladder tissue in rabbits. Sci Rep. 2016;6:20784.

46. Jiang X, Xiong Q, Xu G, et al. VEGF-loaded nanoparticle-modified BAMAs enhance angiogenesis and inhibit graft shrinkage in tissueengineered bladder. Ann Biomed Eng. 2015;43(10):2577-2586. 


\section{Supplementary materials}

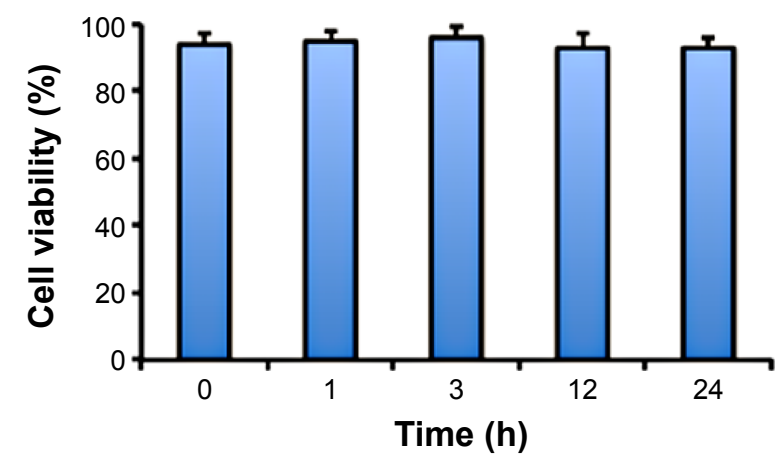

Figure SI Assessment of SPIONs' cytotoxicity on BMSCs.

Notes: Following co-incubation of magnetic nanoparticles with BMSCs (at concentration I50 $\mu \mathrm{g} / \mathrm{mL}$ ) for I, 3, 12 , and $24 \mathrm{~h}$ the toxicity was assessed using MTT assay. Values are expressed as mean \pm SD.

Abbreviations: BMSCs, bone marrow stromal cells; MTT, 3-(4,5-dimethylthiazol-2-yl)-2,5-diphenyltetrazolium bromide; SD, standard deviation; SPIONs, superparamagnetic iron oxide nanoparticles; h, hours.

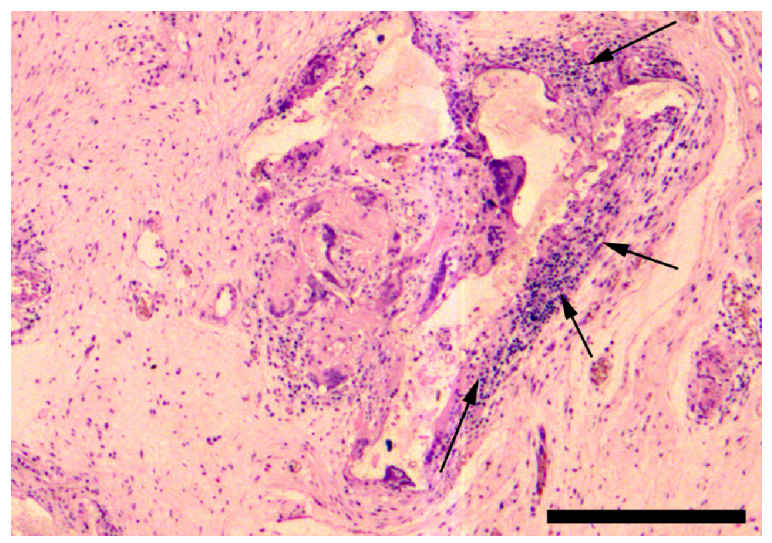

Figure S2 Lymphocytic infiltration at the implantation site of the PL-SF acellular scaffold.

Notes: Infiltration is pointed by black solid arrows. Scale bar, $500 \mu \mathrm{m}$.

Abbreviation: PL-SF, poly-L-lactide/silk fibroin.

International Journal of Nanomedicine

\section{Publish your work in this journal}

The International Journal of Nanomedicine is an international, peerreviewed journal focusing on the application of nanotechnology in diagnostics, therapeutics, and drug delivery systems throughou the biomedical field. This journal is indexed on PubMed Central, MedLine, CAS, SciSearch $®$, Current Contents $\AA /$ Clinical Medicine,

Journal Citation Reports/Science Edition, EMBase, Scopus and the Elsevier Bibliographic databases. The manuscript management system is completely online and includes a very quick and fair peer-review system, which is all easy to use. Visit http://www.dovepress.com/ testimonials.php to read real quotes from published authors. 